\title{
Radiotherapeutic Options for Hepatocellular Carcinoma with Portal Vein Tumor Thrombosis
}

\author{
Dong Soo Lee ${ }^{1}$ Jinsil Seong
}

Department of Radiation Oncology, Yonsei Cancer Center, Yonsei University College of Medicine, Seoul, Republic of Korea

\section{Key Words}

Hepatocellular carcinoma $\cdot$ Portal vein tumor thrombosis $\cdot$ Radiotherapy

\begin{abstract}
Portal vein tumor thrombosis (PVTT) is a common paraneoplastic condition in advanced primary hepatocellular carcinoma or hepatobiliary tract malignancies. Tumors with PVTT are frequently associated with adverse and aggressive features such as intrahepatic tumor dissemination, early treatment failure, or deterioration of hepatic function. Therefore, the treatment outcomes for PVTT in historical series are often dismal and discouraging. More recently, beneficial effects and excellent outcomes of external beam radiation therapy (EBRT) for treating this disease have been reported, and the use of EBRT is becoming more common because of the non-invasive nature of RT and rapid advances in RT technology. We hope to be able to cure this devastating condition in the near future with more advanced and efficacious disease management strategies. The current status and clinical trial results for EBRT as a promising treatment option for managing PVTT will be discussed here. $\quad$ Copyright $\odot 2014$ S. Karger AG, Basel
\end{abstract}

${ }^{1}$ Current affiliation: Seoul St. Mary's Hospital, College of Medicine, The Catholic University of Korea, Seoul, Republic of Korea 


\section{Introduction}

Hepatocellular carcinoma (HCC) is one of the most common neoplasms worldwide, and this is also the case in Asia [1,2]. Although HCC survival rates have been steadily increasing thanks to innovative diagnostic and therapeutic options, the prognosis for patients with this disease remains dismal and discouraging [3-7].

The lifetime cumulative incidence of portal vein thrombosis (PVT) was reported to be approximately $1 \%$ in a population-based study, but this figure increases to $30-40 \%$ when combined with other cancerous conditions such as primary HCC or hepatobiliary tract malignancies [8]. Portal vein tumor thrombosis (PVTT) is now a more commonly and widely used term for PVT associated with those malignancies. The clinical significance of PVTT in HCC patients has been well documented in a number of previous publications. Briefly, the multicentric nature of HCC is commonly associated with PVTT, and, conversely, PVTT or great vessel invasion in HCC also promotes intrahepatic tumor spreading, leading to disease progression, early treatment failure, or deterioration of liver function [9-11]. In addition, the existence of PVTT or intrahepatic vascular invasion in HCC is reflected in the national cancer staging system and implies a more advanced and intractable tumor condition $[12,13]$.

Historically, selected patients with non-bulky, localized PVTT with primary HCC were treated with surgical resection, transarterial chemoembolization (TACE) [14], or intra-arterial chemo-infusion [15] but the outcomes and efficacies were unsatisfactory [16-18].

More recently, beneficial responses and excellent outcomes after external beam radiation therapy (EBRT) in HCC patients have been reported, and EBRT is now officially recommended as one of the therapeutic options for inoperable liver cancer by the National Comprehensive Cancer Network guidelines [19]. In addition, promising results after EBRT have been noted, particularly in PVTT management. Although the effectiveness of EBRT has been limited by low whole-liver radiation tolerance and the low tolerance of adjacent critical structures, the recent development of modern EBRT technologies, including three-dimensional conformal RT (3D-CRT), intensity-modulated RT (IMRT), image-guided RT (IGRT), particle therapies, and improved understanding of the partial volume radiation tolerance of the liver and surrounding organs, has allowed higher doses of EBRT to be delivered with higher precision and without significant increases in treatment-related toxicities [4, 6, 2023]. With these technical improvements, PVTT may become potentially curable by EBRT.

In this review, we discuss the current status and recent results for EBRT as a promising method for PVTT management and consider future strategies to further enhance the therapeutic efficacy of EBRT with respect to PVTT, a commonly encountered difficulty in patients with advanced HCC.

\section{Rationale of PVTT Treatment and an Overview of Non-Radiation-Based Approaches}

Advanced HCC frequently invades the large intrahepatic vessels, including the main PV branches and the hepatic veins, or the inferior vena cava (IVC). PVTT causes partial or complete obstruction of major PV branches, leading to a number of serious complications such as portal hypertension, esophageal variceal bleeding or rupture, intractable ascites, ischemic liver injury, and sudden cardiac death [24].

The median overall survival (OS) of HCC patients with PVTT is reported to be 2-4 months if no further treatment is given [24], which is a very disappointing result. An early report by Mitsunobu et al. [25] showed a strong statistical correlation between intrahepatic metastases and the frequency of vascular invasion. Using radiopaque material injected di- 
rectly into the tumors, they observed flow of the injected material only into the PV in unresectable lesions. These findings demonstrated the possible role of great vessel invasion in the process of pathogenic mechanisms of intrahepatic dissemination or multifocal recurrence in HCC patients.

PVTT in HCC patients has been managed by various treatment options, including local therapy or combined systemic treatment [16-18, 26-28]. In selected patients with good hepatic reserves and non-extensive, localized HCC with PVTT, curable surgical resection can be attempted. However, the majority of patients present with multicentric, multinodular, or disseminated disease states that limit curable surgical approaches. Historically, TACE was regarded as generally unsuitable for HCC with PVTT because of the risk of severe ischemic liver injury. However, recent trials have revealed that TACE can be successfully performed in eligible patients who have well-developed collateral circulation around the main portal branches. Intra-arterial chemo-infusion with 5 -fluorouracil (5-FU) and/or cisplatin (CDDP) or immunotherapy has been attempted and yielded moderate tumor response rates. In addition, intensified chemotherapy delivery methods via TACE have been recently developed [29].

Representative historical results of non-radiation approaches for treating HCC with PVTT are described in table 1 . Surgery as a local therapeutic approach for PVTT was reported in several previous studies [17, 26, 27, 30, 31]. Liu et al. [27] stated that hepatectomy and thrombectomy significantly prolonged OS and recurrence-free survival compared with the group receiving only chemotherapy in patients with HCC and PVTT. The incidence rates of 1-year recurrence in surgery and chemotherapy groups were 27.7 and $70 \%$, respectively. They concluded that hepatectomy and thrombectomy employing total hepatic vascular exclusion was a viable surgical option and resulted in a better quality of life than chemotherapy alone. Lin et al. [26] and Chen et al. [30] also supported the aggressive approach of surgical management and demonstrated successful outcomes in the treatment of PVTT. In contrast, Kondo et al. [17] reported that hepatic resection as a first-choice treatment should be carefully considered in patients with main branch PVTT because no patient with PVTT of the main branch survived for more than 400 days after surgery; surgery in patients with PVTT in the main branch more frequently resulted in severe complications compared with surgery in patients with PVTT in sub-branches.

TACE alone, combined therapy consisting of intraarterial chemo-infusion and systemic immunotherapy, and percutaneous ethanol injection for cure of PVTT were also investigated $[16,18,32]$. Luo et al. [18] performed a prospective comparative study to elucidate the efficacy of TACE compared with conservative treatment alone. A significantly better survival was observed in the TACE group with a 1-year OS rate of $30.9 \%$ compared with $3.8 \%$ in the conservative treatment group. TACE consistently and favorably affected survival outcomes in subgroups with segmental and major PVTT.

Dramatic responses of PVTT to systemic targeted agents have also been reported. Novi et al. [33] and Basso et al. [34] reported a complete response (CR) and recanalization of the PV after treatment with sorafenib and sunitinib, respectively. Yau et al. [28] emphasized the beneficial effect of sorafenib used as a single agent in PVTT control with an $18.2 \%$ partial response (PR) rate and a 13.6\% stable disease (SD) rate in their phase 2 open-label study of sorafenib in an Asian population. In that study, there were no significant differences between patients with and without PVTT in terms of benefit, OS, and toxicity of sorafenib. 





Table 2. Clinical results after radiation therapy to PVTT only

\begin{tabular}{|c|c|c|c|c|c|}
\hline $\begin{array}{l}\text { Authors } \\
\text { [reference] }\end{array}$ & $\begin{array}{l}\text { No. of } \\
\text { patients }\end{array}$ & Treatment & $\begin{array}{l}\text { Total RT dose (range)/ } \\
\text { fractional dose (in Gy) }\end{array}$ & $\begin{array}{l}\text { Response rate } \\
(\mathrm{CR}+\mathrm{PR}, \%)\end{array}$ & $\begin{array}{l}\text { Median survival } \\
\text { (months) }\end{array}$ \\
\hline $\begin{array}{l}\text { Tazawa et al. } \\
{[41]}\end{array}$ & 24 & EBRT+TACE & $50(\mathrm{~N} / \mathrm{A}) / 2$ & 50 (CR 16.7) & $\begin{array}{l}\text { CR/PR (9.7), } \\
\text { NR/PD (3.8) }\end{array}$ \\
\hline $\begin{array}{l}\text { Yamada et al. } \\
{[42]}\end{array}$ & 19 & $\begin{array}{l}\text { 3D-CRT+(TACE for } \\
\text { liver tumor) }\end{array}$ & Mean $57(46-60) / 2$ & 57.9 (CR 0) & 7 \\
\hline $\begin{array}{l}\text { Nakazawa et al. } \\
{[24]}\end{array}$ & 52 & 3D-CRT & $57(39-60)$ & 50 (CR 15.4) & $\begin{array}{l}3 \text {-year survival } \\
15.2 \%\end{array}$ \\
\hline $\begin{array}{l}\text { Zeng et al. } \\
{[43]}\end{array}$ & 44 & RT+TACE & $50(36-60) / 2$ & 45.5 (CR 34.1) & $\begin{array}{l}\text { RT 8, } \\
\text { non-RT } 4\end{array}$ \\
\hline $\begin{array}{l}\text { Katamura et al. } \\
\text { [39] }\end{array}$ & 32 & $\begin{array}{l}\text { iA 5-FU/IFN+3D-CRT/ } \\
\text { iA 5-FU/IFN }\end{array}$ & $39(30-45) / 3$ & $\begin{array}{l}\text { RT 75, } \\
\text { non-RT } 25\end{array}$ & $\begin{array}{l}\text { RT 7.5, } \\
\text { non-RT } 7.9\end{array}$ \\
\hline $\begin{array}{l}\text { Zhang et al. } \\
\text { [44] }\end{array}$ & 45 & $\begin{array}{l}\text { PV stenting+TACE } \\
+3 \mathrm{D}-\mathrm{CRT} / \mathrm{PV} \\
\text { stenting+TACE }\end{array}$ & $40(30-60) / 2$ & 35.6 (CR 0) & $\begin{array}{l}\text { RT } 16.5 \\
\text { non-RT } 4.8\end{array}$ \\
\hline
\end{tabular}

$\mathrm{RT}=$ radiation therapy; $\mathrm{NR}=$ no response $\mathrm{PD}=$ progressive disease; $\mathrm{i}$ = intra-arterial; $\mathrm{IFN}=$ interferon.

\section{Role of Radiation Therapy: Clinical Outcomes of 3D-CRT for Treatment of PVTT with or without an Encompassing Primary Liver Tumor}

Numerous studies of EBRT for treatment of HCC with PVTT have resulted in good responses and promising treatment outcomes [4, 11, 21, 35-37]. The rationale of targeting PVTT in HCC patients using EBRT is the restoration of PV patency and inhibition of further tumor growth or spread into the intrahepatic or intravascular areas. Further treatments (e.g., TACE) may be considered after or before restoring PV patency. Additionally, recent advances in IGRT and IMRT techniques contributed to high-dose and highly focused EBRT delivery while simultaneously minimizing the risk of severe toxicities [4, 38]. These approaches have made PVTT in HCC patients a potentially curable disease.

Several previous publications have reported outcomes of PVTT treated with or without 3D-CRT [39-44]. Table 2 summarizes the clinical results after EBRT for treatment of PVTT only with or without other treatments. Use of 3D-CRT as a sole therapeutic option for targeting PVTT was rarely reported, suggesting an inadequate beneficial effect of EBRT alone for that condition. In a report by Nakagawa et al. [40], 52 patients received PV invasion-targeting treatment using a median 57 Gy of 3D-CRT in a daily dose of 2 Gy; CR/PR was achieved in 26 (50\%) patients and the 3-year OS rate was $15.2 \%$. Multivariate analysis indicated that significant prognostic factors for OS were the number of tumor foci and TACE after EBRT. Traditionally, TACE was used either before or after EBRT to more effectively eradicate and sterilize residual lesions. Response rates for EBRT with TACE ranged from 45-60\%, and median OS rates ranged from 8-10 months. In a more recent study by Zhang et al. [44], the efficacy of percutaneous transhepatic PV stenting and TACE with or without 3D-CRT was evaluated. The objective response rate was $35.6 \%$ (CR+PR), and more durable stent patency was observed when treatment was combined with 3D-CRT. The median OS in the group with combined PV stenting and 3D-CRT was 16.5 months, a promising result. In another report by Katamura et al. [39], intra-arterial 5-FU with interferon- $\alpha$ was combined with 3D-CRT, and the efficacy of 
Table 3. Clinical results after RT to both the PVTT and primary liver tumor

\begin{tabular}{|c|c|c|c|c|c|}
\hline $\begin{array}{l}\text { Authors } \\
\text { [reference] }\end{array}$ & $\begin{array}{l}\text { No. of } \\
\text { patients }\end{array}$ & Treatment & $\begin{array}{l}\text { Total RT dose (range)/ } \\
\text { fractional dose (in Gy) }\end{array}$ & $\begin{array}{l}\text { Response rate } \\
(\mathrm{CR}+\mathrm{PR}, \%)\end{array}$ & $\begin{array}{l}\text { Median survival } \\
\text { (months) }\end{array}$ \\
\hline $\begin{array}{l}\text { Ishikura } \\
\text { et al. [10] }\end{array}$ & 20 & EBRT+TACE & $50(\mathrm{~N} / \mathrm{A}) / 2$ & $50(\mathrm{CR} 0)$ & 5.3 \\
\hline $\begin{array}{l}\text { Kim et al. } \\
{[21]}\end{array}$ & 59 & 3D-CRT & N/A $(30-54) / 2-3$ & 45.8 (CR 6.8) & $\begin{array}{l}\text { Responders 10.7, } \\
\text { non-responders } \\
5.3\end{array}$ \\
\hline $\begin{array}{l}\text { Kim et al. } \\
{[36]}\end{array}$ & 41 & 3D-CRT & $54(44-54) / 2-3$ & 39 (CR 9.7) & $\begin{array}{l}\text { Responders 20.1, } \\
\text { non-responders } \\
7.2\end{array}$ \\
\hline $\begin{array}{l}\text { You et al. } \\
{[48]}\end{array}$ & 49 & 3D-CRT+TACE & N/A $(40-45) / 1.8-2$ & 48 (CR 0) & $\begin{array}{l}\text { TACE } 13, \\
\text { TACE+RT } 13.5\end{array}$ \\
\hline $\begin{array}{l}\text { Toya et al. } \\
{[46]}\end{array}$ & 38 & 3D-CRT & $40(17.5-50.4) / 1.8-4$ & 44.7 (CR 15.8) & 9.6 \\
\hline $\begin{array}{l}\text { Yu et al. } \\
{[37]}\end{array}$ & 281 & 3D-CRT+TACE & N/A (30-54)/1.8-4.5 & 53.8 (CR 3.6) & $\begin{array}{l}\text { Responders 22, } \\
\text { non-responders } 5\end{array}$ \\
\hline $\begin{array}{l}\text { Yoon et al. } \\
{[11]}\end{array}$ & 412 & 3D-CRT+TACE & $40(21-60) / 2-5$ & 27.9 (CR 3.6) & 10.6 \\
\hline
\end{tabular}

this combined treatment was compared with a non-RT group (matched controls). The objective response rate of PVTT was higher in the RT group, i.e., $75 \%$ in the RT group and $25 \%$ in the non-RT group. However, median OS was not significantly different between the two study arms (7.5 months in the RT group vs. 7.9 months in the non-RT group).

Clinical results of previous studies targeting PVTT and primary liver tumors are summarized in table 3. Han et al. [35] performed a clinical pilot study of localized concurrent chemoradiation with 5-FU followed by hepatic arterial chemo-infusion with 5-FU and CDDP for locally advanced HCC with PVTT. The 1 month objective response rate in an intention-totreat analysis was $45 \%$, with a median survival time of 13.1 months. Patients who responded to localized chemoradiation therapy showed significantly better survival outcomes $(\mathrm{p}=$ $0.033)$ than non-responders. Among 40 recruited patients, 12 patients $(30 \%)$ had intrahepatic tumor recurrence, the majority of which developed recurrence in an area outside the RT field. Kim et al. [21] reported a response rate for PVTT treatment of $45.8 \%$ with $6.8 \%$ CR using a 30-54 Gy 3D-CRT dose given in 2-3 Gy fractions. The response rate was statistically higher $(54.6 \%)$ for those treated with a dose greater than or equal to the biologically equivalent dose (BED) of 58 Gy in an $\alpha / \beta$ ratio of 10 compared with those treated with less than 58 Gy (20\%). The median OS in responders and non-responders was 10.7 and 5.3 months, respectively $(\mathrm{p}=0.05)$. Yu et al. [37] suggested a prognostic model based on the retrospective review of 281 HCC patients with PVTT. In their report, a total RT dose of 30-54 Gy was given in 1.8-4.5 Gy daily fractional doses. PVTT and main intrahepatic masses completely disappeared in $10(3.6 \%)$ patients and PR was achieved in $141(50.2 \%)$ patients. In a multivariate analysis, poor Eastern Cooperative Oncology Group (ECOG) performance status, unfavorable Child-Pugh class, multiple tumors, main branch PVTT, complete portal vein occlusion, lymph node metastasis, and large primary tumor size were significantly associated with OS. Prognostic index scores based on these factors correlated well with OS. In a recent large retro- 
spective study performed by Yoon et al. [11], outcomes of 412 patients treated with TACE and 3D-CRT were analyzed. Intrahepatic primary HCC was managed by TACE before or after EBRT with a median total EBRT dose of 40 Gy (range, 21-60 Gy) delivered in 2-5 Gy fractions. The target volume was organized according to the primary tumor size. When the tumor burden was small or TACE was incomplete, the gross tumor volume (GTV) included the entire HCC and PVTT. On the other hand, with large, infiltrative HCC with PVTT a 2- to 3-cm margin into the contiguous HCC was included in the generation of the GTV. CR and PR rates were found to be 3.6\% and 24.3\%, respectively. Grade 3-4 hepatic toxicity during EBRT or within 3 months after completion of EBRT was 10\%. Overall, Yoon et al. concluded that TACE and EBRT combination treatment was a safe and effective option for PVTT management in patients with HCC.

The majority of previous trials evaluated response rates and survival outcomes. However, different methods of response evaluation and the heterogeneous compositions of additional treatments among different studies made it difficult to accurately assess treatment responses. Moreover, the optimal timing of response evaluation and accurate determination of the radiographic response are still debatable. Effects on the OS according to PVTT response are more clear, with a modest benefit in OS in PVTT responders. In terms of RT volume, encompassing both the primary tumor and the PVTT seems to be reasonable approach within allowable bounds of EBRT dose limits.

\section{Dose-Response of PVTT to Radiation Therapy}

Although the response of PVTT to the chosen treatment was one of the main end-points in the majority of studies, the dose-response relationship to 3D-CRT was not routinely evaluated. The reason for this is most likely the common employment of other combination therapies (e.g., TACE) or a relatively homogeneous EBRT dose administration in patient cohorts within studies. The association between the total delivered EBRT dose and the patient's performance status or other confounding factors must be carefully evaluated.

Several studies evaluated dose-response with 3D-CRT alone for the treatment of PVTT $[21,36,45,46]$. Because the fractional dose was different among studies, the BED equation was most frequently utilized using an $\alpha / \beta$ ratio of 10 to estimate dose-response. Toya et al. [46] reported that the response rate and OS was substantially higher in patients who received a $\mathrm{BED}_{10} \geq 58$ Gy than in those who received a $\mathrm{BED}_{10}<58 \mathrm{~Gy}$. The size of the tumor thrombus was also a significant factor when evaluating the treatment of PVTT. In a publication by Kim et al. [36], no objective response was observed in patients receiving a $\mathrm{BED}_{10}<64 \mathrm{~Gy}$, but an objective response rate of $50 \%$ was achieved in patients receiving a $\mathrm{BED}_{10} \geq 64 \mathrm{~Gy}$. Although the BED was not significantly correlated with OS, a trend towards longer survival was observed in patients receiving a $\mathrm{BED}_{10} \geq 64 \mathrm{~Gy}$ (11.2 months vs. 6.8 months, $\mathrm{p}=0.140$ ). Kim et al. [21] also observed a dose-dependent response for the treatment of PVTT. The objective response of PVTT was $20 \%$ with a $\mathrm{BED}_{10}<58$ Gy and $54.6 \%$ with a $\mathrm{BED}_{10} \geq 58 \mathrm{~Gy}$. Responders (CR+PR) lived longer with a median OS of 10.7 months compared with non-responders with a median OS of 5.3 months $(p=0.05)$. More recently, Rim et al. [45] reported successful and promising outcomes with high-dose 3D-CRT for PVTT. The median BED $_{10}$ was $72.2 \mathrm{~Gy}$ and the objective response rate was $62.3 \%$. 


\section{Efficacy and Toxicity of PVTT Treatment with Radiation Therapy}

Historical data have shown that PVTT without further treatment results in poor survival outcomes, with a median OS of only 2-4 months [24]. Direct comparison of outcomes between a cohort of untreated and treated patients has never been performed, because it seems rational to appropriately manage this debilitating condition at the earliest possibly opportunity. The objective estimation of PVTT treatment efficacy is complicated, and the majority of trials evaluated objective response rates using changes in tumor diameter and related survival outcomes as an assessment of treatment response.

The response of PVTT to 3D-CRT alone was separately evaluated in a publication by Kim et al. [36]. The objective response rate of PVTT treatment was 39\% with a 9.7\% CR rate. With respect to HCC, the primary tumor response rate was $54.3 \%$ with a $5.7 \%$ CR rate. Kim et al. [21] also reported an objective PVTT treatment response rate to 3D-CRT of $45.8 \%$ with a $6.8 \%$ CR rate. Hou et al. [47] explored the relationship between PVTT location and EBRT response. Patients with IVC thrombus had a better response rate and longer survival than those with PVTT.

Combination therapy including 3D-CRT and TACE with or without other therapies is commonly utilized for the treatment of PVTT with the goal of more effective disease obliteration [11, 35, 37, 43, 48]. Han et al. [35] announced that the response rate was 45\%, with no patients achieving CR, after localized chemoradiation only. However, $10 \%$ of the patient cohort achieved CR after additional hepatic arterial infusion chemotherapy. Zeng et al. [43] reported an objective response rate of $45.5 \%$ for PVTT treatment by 3D-CRT plus TACE. Yu et al. [37] reported a response rate of $53.8 \%$ with a CR of $3.6 \%$ in their study. You et al. [48] reported a 3-month objective response rate of 48\% with 3D-CRT plus TACE compared with $18.2 \%$ with 3D-CRT alone. Yoon et al. [11] stated that a $39.6 \%$ response rate could be achieved with a CR of $6.6 \%$ with 3D-CRT plus TACE. They also reported that the progressionfree rate of patients with PVTT was a promising 85.6\%. Representative images of CR of PVTT after concurrent chemoradiation are shown in figure 1.

The integration of EBRT and TACE evidently appeared to increase the response rate and OS in patients with PVTT compared with EBRT alone or TACE alone. Zeng et al. [43] reported a CR of $34.1 \%$ when EBRT and TACE were combined, and patients achieved significantly enhanced survival durations. Interestingly, they reported that patients with untreated IVC tumor thrombi survived a median of 2 months, but EBRT served as a significant protective factor for prolonging OS duration to a median 22 months. You et al. [48] similarly described enhanced response rates of up to $48 \%$ with the addition of EBRT. However, the effect of combined therapy using EBRT and TACE on OS was unclear in their report.

Treatment-related toxicities were reported in most studies, but specific toxic effects of PVTT treatment were seldom found, and most cases were of non-specific liver toxicities or were associated with RT-related toxicity. Non-specific gastrointestinal side effects such as anorexia, nausea, or vomiting were the most commonly reported. However, these were well managed with proper medications or temporary rest from EBRT and were not usually a treatment-limiting factor. Although endoscopic findings revealed frequent gastroduodenal mucosal changes after EBRT, high-grade gastric or duodenal ulcer bleeding or perforation was rare, with a frequency of less than $1 \%[42,49]$. However, a causal relationship between toxicity and EBRT dose was not demonstrated. Yamada et al. [42] studied the use of an anteroposterior parallel opposing field treatment design and reported an increased risk of gastroduodenal ulceration or bleeding. Severe hematologic toxicity associated with the use of high dose intra-arterial chemotherapeutic agents [39] and transient liver enzyme elevations were also reported. Kim et al. [36] reported that in most cases of liver enzyme elevation, the levels were less than five-fold the upper normal limit and the elevation was usually self-lim- 

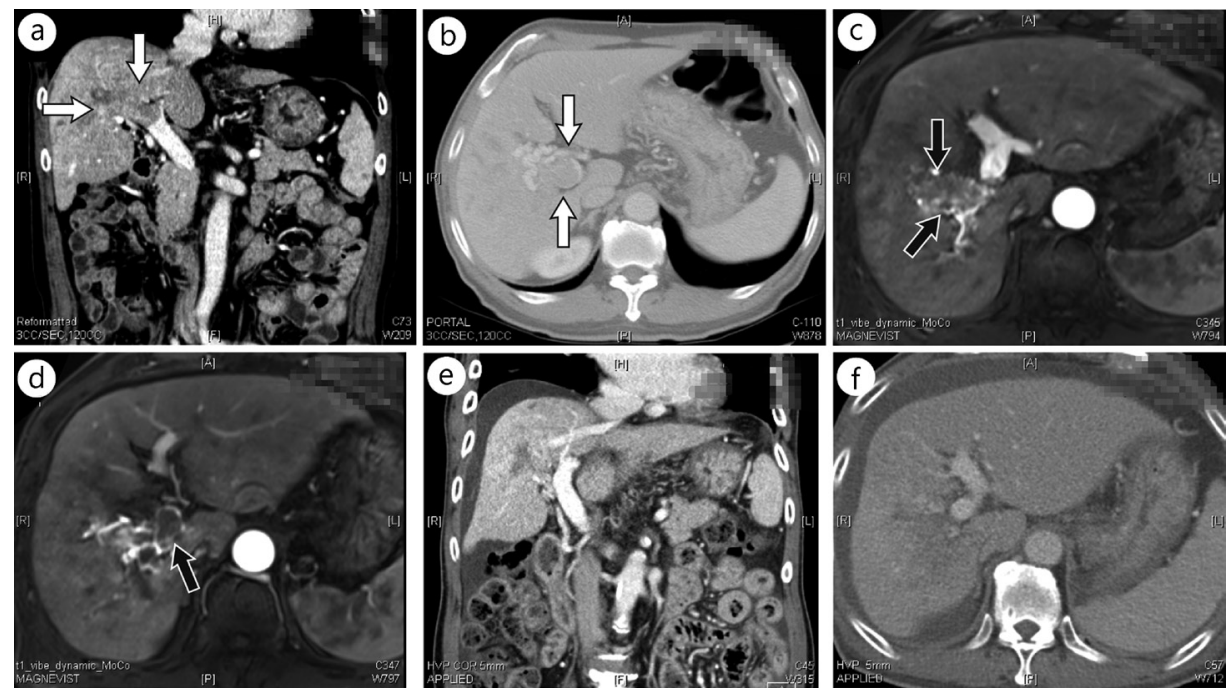

Fig. 1. Computed tomography (CT) and magnetic resonance images (MRI) of a patient showing complete response of PVTT to concurrent chemoradiation. A 70-year-old man was diagnosed with HCC with PVTT in the right main PV trunk and its subsegmental branches. He received definitive aimed concurrent chemoradiation of 45 Gy in 25 fractions with two cycles of intra-arterial 5-fluorouracil. Pretreatment $\alpha$-fetoprotein and PIVKA-II levels of $22.6 \mathrm{ng} / \mathrm{ml}$ and $11097 \mathrm{ng} / \mathrm{ml}$ decreased to 10.8 and $111 \mathrm{ng} / \mathrm{ml}$, respectively, 3 months after chemoradiation. A nearly complete PVTT response was evident in follow-up images at 3 months. (a, b) Pretreatment CT images, (c, d) pretreatment MRIs, and (e, f) CT images 3 months after completion of chemoradiation are shown. Arrows indicate PVTT.

ited. The incidence of high-grade (grade $\geq 3$ ) liver toxicity was $5.7 \%$. Anicteric ascites without elevation of alkaline phosphatase was also recorded. Hepatitis B virus reactivation after liver EBRT is also a well-described adverse event [11]; however, new-generation anti-viral agents effectively mitigate the condition. Discrimination of radiation-induced liver disease from the worsening of liver function associated with tumor progression or adverse effects of EBRT is sometimes challenging because of multiple comorbidities after treatment. Lethal conditions such as thrombus embolism after EBRT for treatment of HCC with IVC or atrial thrombi have been observed because of the high risk of dislodged thrombi [43].

\section{Hypofractionated or Proton-Beam Radiation Therapy Techniques for Targeting PVTT}

Modified fractional radiation schemes with delivery of a large fractional dose greater than the conventional 1.8-2 Gy fraction doses are referred to as hypofractionation. Although hypofractionated EBRT or stereotactic body radiotherapy (SBRT) for primary HCC targeting has been broadly studied, the use of these regimens for PVTT treatment has rarely been reported [4, 38, 50]. Choi et al. [4] demonstrated the feasibility of SBRT for PVTT ablation. In their report, a median dose of 36 Gy (range, 30-39 Gy) given in three consecutive fractions was employed. The CR rate of PVTT was $11.1 \%$ and the median OS of patients with advanced HCC with PVTT was 12 months. No patient experienced grade 4 treatment toxicity. In their long-term follow-up study [38], additional patients were enrolled. Although not analyzed separately from the primary HCC, small tumor volumes of less than $32 \mathrm{~cm}^{3}$ significantly correlated with better in-field tumor response rates and superior in-field progression- 
free survival (PFS). The in-field PFS rate at 1-year follow-up was $81.1 \%$ in tumor volumes $<32 \mathrm{~cm}^{3}$ compared with $38.9 \%$ when volumes were $\geq 32 \mathrm{~cm}^{3}$. No patient experienced severe treatment-related toxicity after long-term follow-up. Wu et al. [50] combined TACE and a hypofractionated schedule of EBRT with a 4-8 Gy fractional dose according to tumor volume. The objective response rate was $71.4 \%$ with a median OS of 11 months.

Because of the close anatomical proximity to critical structures (e.g., the duodenum, other parts of the small bowel, large vessels) and continuous movement of liver parenchyma resulting from the respiratory motion or normal bowel movement, PVTT targeting by highly ablative SBRT doses requires highly precise IGRT techniques. Although highly focused tumor tracking targeting equipment has been developed, previous image-guided technical systems (e.g., the old-generation CyberKnife) usually required the implantation of gold fiducial markers to act as radiographic landmarks; the insertion of such markers required additional laborious procedures with risks of procedure-related complications. Recently, immobilization vacuum body fixation devices combined with four-dimensional CT and various respiration regulatory techniques have been being used to reduce set-up errors and to increase target volume delineations [51,52].

Proton-beam therapy utilizes another type of radiation with a unique physical energy peak property, termed the Bragg peak. The characteristics of the Bragg peak permit excellent dose distribution and localization within a target area without significant increases in normal tissue toxicity. Using this technique, promising treatment outcomes have been achieved in several types of cancer including HCC [22, 53, 54]. Sugahara et al. [55] studied protonbeam RT in HCC with PVTT and obtained excellent results with a median local PFS of 21 months and median OS of 22 months. Of the 35 enrolled patients, 32 remained progressionfree during a median follow-up of 21 months.

\section{Unresolved Issues and Future Strategies of PVTT Treatment}

Many former trials investigated the role of EBRT in PVTT management. However, several issues have yet to be resolved in terms of more efficient PVTT control in the setting of HCC. Optimal dose-fraction schemes, appropriate target coverage, and proper combination of systemic agents should be further examined. Despite continuing efforts to identify strong factors contributing to the treatment response, results are still unclear and ambiguous among studies. Because many study designs and enrolled cohorts are heterogeneous, it becomes difficult to interpret results consistently and uniformly. For example, the size or location of PVTT, underlying hepatic function, and the extent of primary HCC were different among studies, and proper analysis and comparison between studies required careful and judicious interpretation. In the modern therapeutic era, the best strategy is to achieve minimal toxicity and concomitantly to increase treatment efficacy. Because of the high probability of intrahepatic and distant seeding in HCC associated with PVTT, highly effective local therapy combined with systemic agents may be reasonable therapeutic options in the future. We are currently awaiting results of a trial of administration of both sorafenib [28] [the only Food and Drug Administration (FDA)-approved targeted agent in advanced HCC] and highdose, high-precision EBRT for PVTT treatment. Continuous development of radiotherapeutic, chemotherapeutic, and diagnostic imaging techniques may enhance therapeutic ratios and improve treatment outcomes in the future. 


\section{Conclusions}

Looking at the results of previous studies, it is clear that there is not yet a definitive or optimized policy for management of PVTT while treatment modalities and techniques are continuously evolving. However, the use of EBRT is becoming more common because of the non-invasive nature of RT, recognition of high treatment efficacy, and rapid advances in RT technology. With regard to the radiotherapeutic aspect, delivering as much radiation as can be tolerated by surrounding normal tissue and combining radiation with other systemic therapeutic modalities may be more reliable and associated with better treatment outcomes. More individualized approaches are necessary that take into account the location and size of the PVTT as well as the primary HCC status. If primary tumors are small $\left(30-40 \mathrm{~cm}^{3}\right)$ and are close to the PVTT, designing treatment to cover both targets with highly precise and high-dose RT techniques (e.g., image-guided SBRT) is preferable. However, in locally advanced large-volume HCC with PVTT, a more protracted and conservative conventional fractionated 3D-CRT approach seems reasonable. In patients with good hepatic reserve and appropriate performance status, more attempts at curative treatment including intensified chemo-radiotherapy should be performed if possible. Additionally, it is necessary to control subsequent intrahepatic disease dissemination and distant metastasis more efficaciously because those sites are major areas of treatment failure in the era of modern high-dose RT. In the next generation of treatment, we expect to see improved treatment outcomes of PVTT by more refined, stateof-the-art systems of modern EBRT techniques with the integration of novel systemic agents. We hope to be able to cure this devastating condition in the near future with improved understanding of the disease and more advanced and efficacious disease management strategies.

\section{Acknowledgments}

This work was supported by a grant (0620390) from the National R\&D Program for Cancer Control, Ministry of Health and Welfare, Republic of Korea.

\section{References}

-1 Jung KW, Park S, Kong HJ, Won YJ, Lee JY, Seo HG, Lee JS: Cancer statistics in Korea: incidence, mortality, survival, and prevalence in 2009. Cancer Res Treat 2012;44:11-24.

2 Siegel R, Naishadham D, Jemal A: Cancer statistics, 2012. CA Cancer J Clin 2012;62:10-29.

-3 Bashir MR, Gupta RT, Davenport MS, Allen BC, Jaffe TA, Ho LM, Boll DT, Merkle EM: Hepatocellular carcinoma in a North American population: Does hepatobiliary MR imaging with Gd-EOB-DTPA improve sensitivity and confidence for diagnosis? J Magn Reson Imaging. 2013;37:398-406.

-4 Choi BO, Choi IB, Jang HS, Kang YN, Jang JS, Bae SH, Yoon SK, Chai GY, Kang KM: Stereotactic body radiation therapy with or without transarterial chemoembolization for patients with primary hepatocellular carcinoma: preliminary analysis. BMC Cancer 2008;8:351.

5 Corvalan AH: Early diagnosis of hepatocellular carcinoma by microRNAs: shining a light from the genome's "dark matter". Dig Dis Sci 2012;57:2737-2739.

-6 Hawkins MA, Dawson LA: Radiation therapy for hepatocellular carcinoma: from palliation to cure. Cancer 2006;106:1653-1663.

7 Seong J: Challenge and hope in radiotherapy of hepatocellular carcinoma. Yonsei Med J 2009;50:601-612.

-8 Ogren M, Bergqvist D, Björck M, Acosta S, Eriksson H, Sternby NH: Portal vein thrombosis: prevalence, patient characteristics and lifetime risk: a population study based on 23,796 consecutive autopsies. World J Gastroenterol 2006;12:2115-2119.

-9 Fan J, Wu ZQ, Tang ZY, Zhou J, Qiu SJ, Ma ZC, Zhou XD, Ye SL: Multimodality treatment in hepatocellular carcinoma patients with tumor thrombi in portal vein. World J Gastroenterol 2001;7:28-32.

10 Ishikura S, Ogino T, Furuse J, Satake M, Baba S, Kawashima M, Nihei K, Ito Y, Maru Y, Ikeda H: Radiotherapy after transcatheter arterial chemoembolization for patients with hepatocellular carcinoma and portal vein tumor thrombus. Am J Clin Oncol 2002;25:189-193. 
11 Yoon SM, Lim YS, Won HJ, Kim JH, Kim KM, Lee HC, Chung YH, Lee YS, Lee SG, Park JH, Suh DJ: Radiotherapy plus transarterial chemoembolization for hepatocellular carcinoma invading the portal vein: longterm patient outcomes. Int J Radiat Oncol Biol Phys 2012;82:2004-2011.

12 Hsu CY, Hsia CY, Huang YH, Su CW, Lin HC, Lee PC, Loong CC, Chiang JH, Huo TI, Lee SD: Selecting an optimal staging system for hepatocellular carcinoma: comparison of 5 currently used prognostic models. Cancer 2010;116:3006-3014.

13 Kim BK, Kim SU, Park JY, Kim do Y, Ahn SH, Park MS, Kim EH, Seong J, Lee do Y, Han KH: Applicability of BCLC stage for prognostic stratification in comparison with other staging systems: single centre experience from long-term clinical outcomes of 1717 treatment-naive patients with hepatocellular carcinoma. Liver Int 2012;32:1120-1127.

14 Lencioni R: Chemoembolization in patients with hepatocellular carcinoma. Liver Cancer 2012;1:41-50.

15 Kudo M: Treatment of advanced hepatocellular carcinoma with emphasis on hepatic arterial infusion chemotherapy and molecular targeted therapy. Liver Cancer 2012;1:62-70.

16 Chung YH, Song IH, Song BC, Lee GC, Koh MS, Yoon HK, Lee YS, Sung KB, Suh DJ: Combined therapy consisting of intraarterial cisplatin infusion and systemic interferon-alpha for hepatocellular carcinoma patients with major portal vein thrombosis or distant metastasis. Cancer 2000;88:1986-1991.

17 Kondo K, Chijiiwa K, Kai M, Otani K, Nagaike K, Ohuchida J, Hiyoshi M, Nagano M: Surgical strategy for hepatocellular carcinoma patients with portal vein tumor thrombus based on prognostic factors. Journal Gastrointest Surg 2009;13:1078-1083.

18 Luo J, Guo RP, Lai EC, Zhang YJ, Lau WY, Chen MS, Shi M: Transarterial chemoembolization for unresectable hepatocellular carcinoma with portal vein tumor thrombosis: a prospective comparative study. Ann Surg Oncol 2011;18:413-420.

19 Benson AB 3rd, Abrams TA, Ben-Josef E, Bloomston PM, Botha JF, Clary BM, Covey A, Curley SA, D’Angelica MI, Davila R, Ensminger WD, Gibbs JF, Laheru D, Malafa MP, Marrero J, Meranze SG, Mulvihill SJ, Park JO, Posey JA, Sachdev J, Salem R, Sigurdson ER, Sofocleous C, Vauthey JN, Venook AP, Goff LW, Yen Y, Zhu AX: NCCN clinical practice guidelines in oncology: hepatobiliary cancers. J Natl Compr Canc Netw 2009;7:350-391.

-20 Dawson LA, Ten Haken RK: Partial volume tolerance of the liver to radiation. Semin Radiat Oncol 2005;15:279-283.

21 Kim DY, Park W, Lim DH, Lee JH, Yoo BC, Paik SW, Kho KC, Kim TH, Ahn YC, Huh SJ: Three-dimensional conformal radiotherapy for portal vein thrombosis of hepatocellular carcinoma. Cancer 2005;103:24192426.

22 Sugahara S, Oshiro Y, Nakayama H, Fukuda K, Mizumoto M, Abei M, Shoda J, Matsuzaki Y, Thono E, Tokita $\mathrm{M}$, Tsuboi K, Tokuuye K: Proton beam therapy for large hepatocellular carcinoma. Int J Radiat Oncol Biol Phys 2010;76:460-466.

23 Jihye C, Jinsil S: Application of radiotherapeutic strategies in the BCLC-defined stages of hepatocellular carcinoma. Liver Cancer 2012;1:216-225.

24 Nakazawa T, Adachi S, Kitano M, Isobe Y, Kokubu S, Hidaka H, Ono K, Okuwaki Y, Watanabe M, Shibuya A, Saigenji K: Potential prognostic benefits of radiotherapy as an initial treatment for patients with unresectable advanced hepatocellular carcinoma with invasion to intrahepatic large vessels. Oncology 2007;73:90-97.

25 Mitsunobu M, Toyosaka A, Oriyama T, Okamoto E, Nakao N: Intrahepatic metastases in hepatocellular carcinoma: the role of the portal vein as an efferent vessel. Clin Exp Metastasis 1996;14:520-529.

26 Lin DX, Zhang QY, Li X, Ye QW, Lin F, Li LL: An aggressive approach leads to improved survival in hepatocellular carcinoma patients with portal vein tumor thrombus. J Cancer Res Clin Oncol 2011;137:139-149.

27 Liu J, Wang Y, Zhang D, Liu B, Ou Q: Comparison of survival and quality of life of hepatectomy and thrombectomy using total hepatic vascular exclusion and chemotherapy alone in patients with hepatocellular carcinoma and tumor thrombi in the inferior vena cava and hepatic vein. Eur J Gastroenterol Hepatol 2012;24:186-194.

28 Yau T, Chan P, Ng KK, Chok SH, Cheung TT, Fan ST, Poon RT: Phase 2 open-label study of single-agent sorafenib in treating advanced hepatocellular carcinoma in a hepatitis B-endemic Asian population: presence of lung metastasis predicts poor response. Cancer 2009;115:428-436.

-29 Song MJ, Chun HJ, Song S, Kim HY, Yoo SH, Park CH, Bae SH, Choi JY, Chang UI, Yang JM, Lee HG, Yoon SK: Comparative study between doxorubicin-eluting beads and conventional transarterial chemoembolization for treatment of hepatocellular carcinoma. J Hepatol 2012;57:1244-1250.

30 Chen XP, Qiu FZ, Wu ZD, Zhang ZW, Huang ZY, Chen YF, Zhang BX, He SQ, Zhang WG: Effects of location and extension of portal vein tumor thrombus on long-term outcomes of surgical treatment for hepatocellular carcinoma. Ann Surg Oncol 2006;13:940-946.

-31 Matono R, Yoshiya S, Motomura T, Toshima T, Kayashima H, Masuda T, Yoshizumi T, Taketomi A, Shirabe K, Maehara Y: Factors linked to longterm survival of patients with hepatocellular carcinoma accompanied by tumour thrombus in the major portal vein after surgical resection. HPB (Oxford) 2012;14:247-253.

-32 Chan MK, Kwok PC, Chan SC, Lam TW, Lo KK, Lam CL: Percutaneous ethanol injection as a possible curative treatment for malignant portal vein thrombosis in hepatocellular carcinoma. Cardiovasc Intervent Radiol 1999;22:326-328.

-33 Novi M, Lauritano EC, Piscaglia AC, Barbaro B, Zocco MA, Pompili M, Gasbarrini A: Portal vein tumor thrombosis revascularization during sorafenib treatment for hepatocellular carcinoma. Am J Gastroenterol 2009;104:1852-1854. 
34 Basso M, Basso M, Iaculli A, Pompili M, Riccardi L, Barbaro B, Rufini V, Cassano A, Castaldi P, Barone C: Complete metabolic response with recanalization of portal vein tumor thrombosis after sunitinib in a patient with advanced hepatocellular carcinoma. Case reports in oncology 2010;3:391-396.

-35 Han KH, Seong J, Kim JK, Ahn SH, Lee Y, Chon CY: Pilot clinical trial of localized concurrent chemoradiation therapy for locally advanced hepatocellular carcinoma with portal vein thrombosis. Cancer 2008;113:9951003.

-36 Kim TH, Kim DY, Park JW, Kim YI, Kim SH, Park HS, Lee WJ, Park SJ, Hong EK, Kim CM: Three-dimensional conformal radiotherapy of unresectable hepatocellular carcinoma patients for whom transcatheter arterial chemoembolization was ineffective or unsuitable. Am J Clin Oncol 2006;29:568-575.

37 Yu JI, Park HC, Lim H, Park W, Yoo BC, Paik SW, Koh KC, Lee JH: Prognostic index for portal vein tumor thrombosis in patients with hepatocellular carcinoma treated with radiation therapy. J Korean Med Sci 2011;26:1014-1022.

38 Kwon JH, Bae SH, Kim JY, Choi BO, Jang HS, Jang JW, Choi JY, Yoon SK, Chung KW: Long-term effect of stereotactic body radiation therapy for primary hepatocellular carcinoma ineligible for local ablation therapy or surgical resection. Stereotactic radiotherapy for liver cancer. BMC Cancer 2010;10:475.

39 Katamura Y, Aikata H, Takaki S, Azakami T, Kawaoka T, Waki K, Hiramatsu A, Kawakami Y, Takahashi S, Kenjo M, Toyota N, Ito K, Chayama K: Intra-arterial 5-fluorouracil/interferon combination therapy for advanced hepatocellular carcinoma with or without three-dimensional conformal radiotherapy for portal vein tumor thrombosis. J Gastroenterol 2009;44:492-502.

-40 Nakagawa K, Yamashita H, Shiraishi K, Nakamura N, Tago M, Igaki H, Hosoi Y, Shiina S, Omata M, Makuuchi M, Ohtomo K: Radiation therapy for portal venous invasion by hepatocellular carcinoma. World J Gastroenterol 2005;11:7237-7241.

-41 Tazawa J, Maeda M, Sakai Y, Yamane M, Ohbayashi H, Kakinuma S, Miyasaka Y, Nagayama K, Enomoto N, Sato C: Radiation therapy in combination with transcatheter arterial chemoembolization for hepatocellular carcinoma with extensive portal vein involvement. J Gastroenterol Hepatol 2001;16:660-665.

-42 Yamada K, Izaki K, Sugimoto K, Mayahara H, Morita Y, Yoden E, Matsumoto S, Soejima T, Sugimura K: Prospective trial of combined transcatheter arterial chemoembolization and three-dimensional conformal radiotherapy for portal vein tumor thrombus in patients with unresectable hepatocellular carcinoma. Int J Radiat Oncol Biol Phys 2003;57:113-119.

43 Zeng ZC, Fan J, Tang ZY, Zhou J, Qin LX, Wang JH, Sun HC, Wang BL, Zhang JY, Jiang GL, Wang YQ: A comparison of treatment combinations with and without radiotherapy for hepatocellular carcinoma with portal vein and/or inferior vena cava tumor thrombus. Int J Radiat Oncol Biol Phys 2005;61:432-443.

-44 Zhang XB, Wang JH, Yan ZP, Qian S, Du SS, Zeng ZC: Hepatocellular carcinoma with main portal vein tumor thrombus: treatment with 3-dimensional conformal radiotherapy after portal vein stenting and transarterial chemoembolization. Cancer 2009;115:1245-1252.

45 Rim CH, Yang DS, Park YJ, Yoon WS, Lee JA, Kim CY: Effectiveness of high-dose three-dimensional conformal radiotherapy in hepatocellular carcinoma with portal vein thrombosis. Jpn J Clin Oncol 2012;42:721-729.

-46 Toya R, Murakami R, Baba Y, Nishimura R, Morishita S, Ikeda O, Kawanaka K, Beppu T, Sugiyama S, Sakamoto T et al: Conformal radiation therapy for portal vein tumor thrombosis of hepatocellular carcinoma. Radiother Oncol 2007;84:266-271.

47 Hou JZ, Zeng ZC, Zhang JY, Fan J, Zhou J, Zeng MS: Influence of tumor thrombus location on the outcome of external-beam radiation therapy in advanced hepatocellular carcinoma with macrovascular invasion. Int J Radiat Oncol Biol Phys 2012;84:362-368.

48 You CR, Jang JW, Kang SH, Bae SH, Choi JY, Yoon SK, Choi IB, Lee DH, Chun HJ, Choi BG: Efficacy of transarterial chemolipiodolization with or without 3-dimensional conformal radiotherapy for huge HCC with portal vein tumor thrombosis. Korean J Hepatol 2007;13:378-386.

49 Chon YE, Seong J, Kim BK, Cha J, Kim SU, Park JY, Ahn SH, Han KH, Chon CY, Shin SK, Kim Y: Gastroduodenal complications after concurrent chemoradiation therapy in patients with hepatocellular carcinoma: endoscopic findings and risk factors. Int J Radiat Oncol Biol Phys 2011;81:1343-1351.

$50 \mathrm{Wu}$ DH, Chen LH: Efficacy of 3-dimensional conformal hypofractionated single high-dose radiotherapy combined with transcatheter arterial chemoembolization for portal vein tumor thrombus in patients with hepatocellular carcinoma. Chin J Cancer 2004;23:825-828.

51 Lee IJ, Seong J: The optimal selection of radiotherapy treatment for hepatocellular carcinoma. Gut Liver 2012;6:139-148.

52 Xi M, Liu MZ, Zhang L, Li QQ, Huang XY, Liu H, Hu YH: How many sets of 4DCT images are sufficient to determine internal target volume for liver radiotherapy? Radiother Oncol 2009;92:255-259.

53 Kagan AR, Schulz RJ: Proton-beam therapy for prostate cancer. Cancer J 2010;16:405-409.

54 Zenda S, Kohno R, Kawashima M, Arahira S, Nishio T, Tahara M, Hayashi R, Kishimoto S, Ogino T: Proton beam therapy for unresectable malignancies of the nasal cavity and paranasal sinuses. Int J Radiat Oncol Biol Phys 2011;81:1473-1478.

55 Sugahara S, Nakayama H, Fukuda K, Mizumoto M, Tokita M, Abei M, Shoda J, Matsuzaki Y, Thono E, Tsuboi $\mathrm{K}$, et al: Proton-beam therapy for hepatocellular carcinoma associated with portal vein tumor thrombosis. Strahlentherapie und Onkologie. Organ Dtsch Rontgengesellschaft 2009;185:782-788. 